\title{
Predictors of cervical cancer being at an advanced stage at diagnosis in Sudan
}

This article was published in the following Dove Press journal:

International Journal of Women's Health

10 November 2011

Number of times this article has been viewed

\section{Ahmed Ibrahim' \\ Vibeke Rasch ${ }^{2}$ \\ Eero Pukkala ${ }^{3}$ \\ Arja R Aro'}

'Unit for Health Promotion Research, University of Southern Denmark, Esbjerg, Denmark; ${ }^{2}$ Department of Obstetrics and Gynaecology, Odense University Hospital, Odense, Denmark; ${ }^{3}$ Finnish Cancer Registry, Institute for Statistical and Epidemiological Cancer Research, Helsinki, Finland
Correspondence: Ahmed Ibrahim Unit for Health Promotion Research, University of Southern Denmark, Niels Bohrs Vej 9-10, Esbjerg 6700, Denmark

Email aibrahim@health.sdu.dk
Background: Cervical cancer is the second most common cancer among women in Sudan, with more than two-thirds of all women with invasive cervical cancer being diagnosed at an advanced stage (stages III and IV). The lack of a screening program for cervical cancer in Sudan may contribute to the late presentation of this cancer, but other factors potentially associated with advanced stages of cervical cancer at diagnosis are unknown. The purpose of this research was to investigate the relationship between age, marital status, ethnicity, health insurance coverage, residence in an urban vs a rural setting, and stage (at diagnosis) of cervical cancer in Sudan.

Methods: This was a cross sectional study of 197 women diagnosed with different stages of cervical cancer. Data was obtained from the cancer registry unit at the Radiation and Isotopes Centre in Khartoum for all women diagnosed with cervical cancer in 2007.

Results: There was an association between older age and advanced stage (at diagnosis) of cervical cancer (odds ratio [OR]: 1.03, 95\% confidence interval [CI]: 1.01-1.05). Being of African ethnicity was associated with 76\% increased odds (OR: 1.76, 95\% CI: 1.01-3.05), living in a rural area was associated with 13\% increased odds (OR: 1.13, 95\% CI: 1.78-5.50), and being uninsured was associated with an almost eight-fold increase in odds (OR: 7.7, 95\% CI: 3.76-15.38). Marital status and education level were not associated with an advanced stage of cervical cancer at diagnosis.

Conclusion: Women with cervical cancer who are elderly, not covered by health insurance, of African ethnicity, and living in a rural area are more likely to be diagnosed at an advanced stage of cervical cancer in Sudan. These women should be targeted for cervical cancer screening and a health education program, and encouraged to have health insurance.

Keywords: predictors, cervical cancer, diagnosis, advanced, health insurance, Sudan

\section{Introduction}

Cervical cancer is the second most common cancer among women worldwide, with a particularly high incidence in sub-Saharan Africa where there were an estimated 57,000 cases in 2000 , comprising $22 \%$ of all cancers in women. ${ }^{1}$ In many developing countries cervical cancer is not only the most frequently occurring cancer among middle-aged women, but also a leading cause of death, partly due to poor access to medical care and the unavailability of routine screening in many of these countries. ${ }^{2}$ One of the most important prognostic factors is how early the cancer is detected and how far it has spread. Women who undergo annual pelvic examinations and Pap smears have a greater chance of any abnormalities or cancerous tissue being detecting during the early stages, which can play a crucial role regarding the chances of treating the cancer successfully. Lack of cervical screening consequently leads to very advanced disease in African women. ${ }^{3-6}$ Whereas many cancers tend to have a 
high incidence in more urban areas, cervical cancer tends to have a higher incidence in more remote areas. Ethnicity plays an important role in morbidity and mortality from cervical cancer. The mortality rate for women with cervical cancer varies according to race and ethnicity. In 2007 , black women were more likely to die from cervical cancer than any other group of women. Hispanic women had the second highest death rate from cervical cancer, followed by American Indian/Alaska Natives, white, and Asian/Pacific Island women. ${ }^{7}$ Ethnicity and specific cultural barriers play an important role in disparate utilization of cancer health care services. Sociodemographic factors and comorbidity contribute to the probability of experiencing a delay in the diagnosis of cervical and ovarian cancers. The likelihood of a long delay in referral was greater in rural vs urban areas. ${ }^{8}$ Having health insurance has a crucial role in early diagnosis of cervical cancer. Garcés-Palacio et al found that women in Colombia with subsidized health insurance were significantly more likely to seek cervical cancer screening than women without health insurance. ${ }^{9}$ Paolino and Arrossi found that having health insurance and being married were the factors most significantly related to screening for early detection of cervical cancer in Argentina. ${ }^{10}$ Up to $95 \%$ of cancer patients in African countries are diagnosed when they have late-stage or end-stage disease. Delayed diagnosis in these patients is due to the low level of cancer awareness in the population and health workers, culture, and limited access to specialized care, which is close to nonexistent in African countries. ${ }^{6}$

In the absence of a screening program in Sudan, the majority of women with invasive cervical cancer are diagnosed at an advanced stage and factors potentially associated with advanced stage of cervical cancer at diagnosis are unknown. The objective of this study was to identify predictors of cervical cancer already being at an advanced stage at diagnosis in Sudan.

\section{Methods and materials}

This was a cross sectional study of women diagnosed with cervical cancer from January 1, 2007 to December 31, 2007 in Sudan. Data was obtained in January 2009 from the cancer registry at the Radiation and Isotopes Centre in Khartoum, which is the only specialized cancer hospital in Sudan. Suspected or diagnosed cancer cases from all hospitals around Sudan were referred to this center for confirmation of diagnosis and further treatment. All patient information is registered and stored in a database using CanReg4 software, which is also used by the International Agency on Research for Cancer. The study variables were age, marital status, tribe, residence area, state, health insurance status, and tumor staging at diagnosis. Tumors were classified using the FIGO (Fédération Internationale de Gynécologie et d'Obstétrique) classification ${ }^{11}$ as: stage I, confined to the cervix; stage II, extending beyond the cervix, but not into the pelvic wall, involving two-thirds of the upper vagina; stage III, extending into the pelvic wall and involving the lower third of the vagina but not adjacent organs; and stage IV, extending beyond the pelvis into adjacent and distant organs. Staging is based on a combination of anatomical, pathological, operative, and clinical variables.

Patients in the study sample were stratified by geographical residence into urban or rural and also by health insurance status. Patients with health insurance were also stratified according to whether their policy was taken out before or after their diagnosis of cervical cancer. If a patient had health insurance before diagnosis of the disease, she was considered to be insured; if the patient took out health insurance after the diagnosis of cancer she was considered to have been uninsured. This distinction was made to enable assessment of the effect of health insurance on the detection of cervical cancer. The study sample included women from 94 tribes, which were grouped into African and Arabic ethnicity based on the classification of tribes of Sudan. ${ }^{12}$ The main outcome variable for this study was staging of cervical cancer at diagnosis. Variables identified as potential predictors of an advanced stage at diagnosis were age, ethnicity, marital status, urban residence, and health insurance.

\section{Statistical analysis}

The Chi-squared test was used for comparison of proportions and the $t$-test was used to compare mean values. The relationship between predictor variables and disease staging at diagnosis was then examined by logistic regression. The $P$ value, odds ratio (OR) and 95\% confidence interval (CI) were reported. All statistical analyses were performed using Stata (v 10.0; Stata Corporation, College Station, TX).

\section{Results}

The mean age of the patients at diagnosis was 54.5 (range 25-76) years. About $70 \%$ of the women were currently married and more than half were living in a rural area (Table 1). Twenty-seven percent of the women had health insurance. About $72 \%$ of women in the sample were diagnosed with invasive cervical cancer that had spread beyond the cervix. Women diagnosed at an advanced stage of cervical cancer were older than those diagnosed at an earlier stage (Table 1). More than half of the cases were 
Table I Characteristics of 197 women diagnosed with cervical cancer and having data held in the Radiation and Isotopes Centre in Khartoum, Sudan, in 2007

\begin{tabular}{|c|c|}
\hline Characteristics & n (\%) \\
\hline \multicolumn{2}{|l|}{ Age (years) } \\
\hline$\leq 54$ & $73(37.1)$ \\
\hline$\geq 55$ & $124(62.9)$ \\
\hline \multicolumn{2}{|l|}{ Marital status } \\
\hline Single & $60(30.5)$ \\
\hline Married & $137(69.5)$ \\
\hline \multicolumn{2}{|l|}{ Ethnicity } \\
\hline African & $103(52.3)$ \\
\hline Arabic & 94 (47.7) \\
\hline \multicolumn{2}{|l|}{ Education level } \\
\hline Basic school & $122(61.9)$ \\
\hline Secondary school & $75(38.1)$ \\
\hline \multicolumn{2}{|l|}{ Geographical area } \\
\hline Urban & $90(45.7)$ \\
\hline Rural & $107(54.3)$ \\
\hline \multicolumn{2}{|l|}{ Health insurance } \\
\hline Covered & $53(26.9)$ \\
\hline Not covered & I $44(73.1)$ \\
\hline \multicolumn{2}{|l|}{ Tumor morphology } \\
\hline Squamous cell carcinoma & $145(73.6)$ \\
\hline Adenocarcinoma & $52(26.4)$ \\
\hline \multicolumn{2}{|c|}{ Disease stage at diagnosis (FIGO) } \\
\hline Stage I & $17(8.7)$ \\
\hline Stage II & $39(19.8)$ \\
\hline Stage III & $27(13.7)$ \\
\hline Stage IV & II 4 (57.9) \\
\hline
\end{tabular}

diagnosed at stage IV. The proportion of women diagnosed at advanced stages of cervical cancer was higher than those diagnosed at an earlier stage ( $71.5 \%$ vs $28.4 \%)$. Women aged 54 years and older were more frequently diagnosed with advanced cervical cancer compared to those who were younger. Women of African ethnicity were more likely to be diagnosed with stage III-IV disease than Arabic women. Women living in urban areas had a higher chance of being diagnosed earlier than those living in rural areas. Women covered by health insurance were diagnosed more frequently in the early stages of cervical cancer than those not covered by health insurance ( $16.2 \%$ vs $12.2 \%$, respectively). There was a statistically significant difference between the proportion of women covered and not covered by health insurance who were diagnosed at an advanced stage of cervical cancer (60.9\% vs $12.2 \%$, respectively, $P<0.0001$; Table 2 ).

The relationship between predictor variables and staging of cervical cancer at diagnosis was examined using multivariate logistic regression (Table 3). Age, ethnicity, geographical residence, and health insurance status were found to be associated with staging at diagnosis. Older age
Table 2 Distribution of predictors and stages of cervical cancer at diagnosis in 197 Sudanese women

\begin{tabular}{|c|c|c|c|}
\hline Predictor & $\begin{array}{l}\text { Early stages } \\
\text { (I and II) } \\
\mathrm{n}=56(28.4 \%)\end{array}$ & $\begin{array}{l}\text { Advanced stages } \\
\text { (III and IV) } \\
n=|4|(7 I .5 \%)\end{array}$ & $P$ value \\
\hline \multicolumn{4}{|l|}{ Age (years) } \\
\hline$\leq 54$ & 22 (II.1\%) & $5 \mathrm{I}(25.9 \%)$ & 0.8 \\
\hline$\geq 55$ & 34 (I7.3\%) & $90(46.7 \%)$ & \\
\hline \multicolumn{4}{|l|}{ Marital status } \\
\hline Single & $16(8.1 \%)$ & 44 (22.3\%) & 0.7 \\
\hline Married & 40 (20.3\%) & 97 (49.2\%) & \\
\hline \multicolumn{4}{|l|}{ Educational level } \\
\hline Primary school & $34(17.3 \%)$ & 88 (44.6\%) & 0.8 \\
\hline Secondary school & 22 (1।.2\%) & 53 (26.9\%) & \\
\hline \multicolumn{4}{|l|}{ Ethnicity } \\
\hline Arabic & 38 (19.3\%) & $56(28.4 \%)$ & 0.003 \\
\hline African & $18(19.3 \%)$ & 85 (43.1\%) & \\
\hline \multicolumn{4}{|l|}{ Geographical area } \\
\hline Urban & 38 (19.3\%) & 52 (26.4\%) & 0.001 \\
\hline Rural & $18(19.3 \%)$ & $89(45.1 \%)$ & \\
\hline \multicolumn{4}{|l|}{ Health insurance } \\
\hline Insured & $32(16.2 \%)$ & 21 (10.7\%) & 0.0001 \\
\hline Not insured & $24(12.2 \%)$ & 120 (60.9\%) & \\
\hline
\end{tabular}

( $\geq 55$ years) was associated with increased odds of diagnosis at an advanced stage (OR: 1.03, 95\% CI: 1.01-1.05). Rural residence was associated with increased odds of diagnosis at an advanced stage (OR: 1.13, 95\% CI: 1.78-5.50). Diagnosis at an advanced stage was far more likely in women of African ethnicity (OR: 1.76, 95\% CI: 1.01-3.05). Those without health insurance had much higher odds of a diagnosis of cervical cancer at an advanced stage than those with health insurance (OR: 7.7, 95\% CI: 3.76-15.38).

\section{Discussion}

About $72 \%$ of the cervical cancer cases in this Sudanese study were diagnosed at an advanced stage. Older age, lack of insurance, African ethnicity, and rural residence were independent risk factors for the diagnosis of advanced cervical cancer. The risk was especially high in women with no health insurance. This finding is consistent with earlier reports. ${ }^{13-15}$ Women without health insurance were less likely than those with health insurance to seek health care and to receive appropriate treatment. In this study, nearly $46 \%$ of advanced (FIGO stages III and IV) cervical cancer cases were aged over 55 years. Older women were less often diagnosed at an early stage of cervical cancer than younger women. This may be due to older women not seeking obstetrics and gynecology services in the post-menopausal years, and particularly women in rural areas where health care services are not readily accessible. Another likely factor is lack of awareness about cervical cancer. ${ }^{14-21}$ Furthermore, a crucial 
Table 3 Multivariate logistic regression analysis of predictors of cervical cancer staging at diagnosis

\begin{tabular}{|c|c|c|c|c|c|}
\hline Predictor & $\begin{array}{l}\text { Early stages } \\
\text { (I and II) }\end{array}$ & $\begin{array}{l}\text { Advanced stages } \\
\text { (III and IV) }\end{array}$ & $\begin{array}{l}\text { Unadjusted OR } \\
(95 \% \mathrm{Cl})\end{array}$ & $\begin{array}{l}\text { Adjusted OR } \\
(95 \% \mathrm{Cl})\end{array}$ & $P$ value \\
\hline Age $\geq 55$ years & $34(17.3 \%)$ & $90(46.7 \%)$ & I.I (0.60-2.15) & $1.03(1.01-1.05)$ & 0.8 \\
\hline Married & $40(20.3 \%)$ & 97 (49.2\%) & $0.8(0.44-1.74)$ & $0.8(0.43-1.45)$ & 0.7 \\
\hline Primary school & $34(35.1 \%)$ & $88(44.7 \%)$ & $0.9(0.49-1.75)$ & $0.7(0.43-1.32)$ & 0.9 \\
\hline African ethnicity & $18(19.3 \%)$ & $85(43.1 \%)$ & $3.2(1.66-6.16)$ & $1.76(1.01-3.05)$ & 0.003 \\
\hline Rural area & $18(19.3 \%)$ & $89(45.1 \%)$ & $3.7(2.54-9.3 \mathrm{I})$ & $1.13(1.78-5.50)$ & 0.001 \\
\hline No health insurance coverage & $24(12.2 \%)$ & $120(60.9 \%)$ & $8.6(4.55-16.24)$ & $7.7(3.76-15.38)$ & $<0.0001$ \\
\hline
\end{tabular}

Notes: Reference groups: Age $\leq 55$ years, single, secondary school, Arabic ethnicity, urban area, have health insurance coverage.

Abbreviations: $\mathrm{OR}$, odds ratio; $\mathrm{Cl}$, confidence interval.

contributor to delayed detection of cervical cancer is probably poor dissemination of information and communication by health care providers. ${ }^{22-25}$

In this study, women of African ethnicity were more likely to be diagnosed with advanced disease than those of Arabic ethnicity. Ethnic differences in staging at diagnosis of cervical cancer have been reported by several other studies. Brewer et a ${ }^{26}$ found major ethnic differences in survival rates for Maori and Pacific Island women with cervical cancer in New Zealand. They reported that this difference was almost entirely due to staging at diagnosis, indicating that ethnic differences in access to and uptake of screening and treatment of premalignant lesions may have played a role. Brookfield et $\mathrm{al}^{27}$ reported similar findings for a population in Florida that included Caucasian, African-American, and Hispanic women. Their study concluded that racial, ethnic, and socioeconomic disparities in cervical cancer survival rates were explained by late-stage presentation and undertreatment. ${ }^{27}$ In line with our results, Wu et $\mathrm{al}^{28}$ found that certain ethnic groups, ie, Black and Hispanic, as well as older women, were more likely to be diagnosed with late-stage cervical cancer. This difference is due to lack of awareness, poverty, and lack of health insurance, resulting in an underprivileged situation in terms of access to health care services. In our study, there was a difference in geographical distribution between women of African and Arabic ethnicity, but the spatial distribution of African and Arab ethnicity in Sudan (with respect to hospital care) is equal. Spatial disparity in access to health services exists between urban and rural areas in Sudan but there is no clear evidence that populations of African ethnicity concentrate in rural areas. There is a lack of access to health services and health insurance cover in rural areas and this probably contributes to late presentation, again resulting in diagnosis of cervical cancer at an advanced stage.

Single women in Sudan are not usually sexually active and rarely seek reproductive health care, so are unlikely to have regular gynecological examinations. Due to an inherent social stigma about loss of virginity, unmarried women are considered to be virgins. Unmarried women may avoid undergoing a gynecological examination for fear of being stigmatized if it is discovered that they are sexually active. ${ }^{29}$ Moreover, social mores in Sudan consider sex outside marriage to be sinful, and are widely suspected to affect health care being sought for gynecological symptoms, which are often associated with sexually transmitted infections. ${ }^{30}$ In this study, married women were more likely to be diagnosed at early stages of cervical cancer compared with unmarried women, which may be due to the more frequent obstetric and gynecological care they receive during their childbearing years.

There are some limitations to this study. First, data on earlier staging of cervical cancer, such as carcinoma in situ, are not held by the cancer registry, and the tumor stages were classified into broad major stages without substaging. Second, invasive cervical cancer cases were reported to the cancer registry directly from secondary and tertiary care institutions, so data on patients who were not hospitalized would not have been entered into this hospital-based registry. The extent to which unregistered cases may have differed in age, ethnicity, and geographical distribution is unknown.

\section{Conclusion}

Women with cervical cancer who are elderly, not covered by health insurance, of African ethnicity, and living in rural areas are more likely to be diagnosed at an advanced stage of cervical cancer in Sudan. These women should be targeted for cervical cancer screening and health education programs and encouraged to take out health insurance cover.

\section{Disclosure}

The authors report no conflicts of interest in this work. 


\section{References}

1. Parkin DM, Ferlay J, Hamdi-Cherif M, et al. Cancer in Africa: Epidemiology and Prevention. International Agency for Research on Cancer Scientific Publication No. 153. France, Lyon: International Agency for Research on Cancer Press; 2003.

2. Chi DS, Lanciano RM, Kudelka AP. Cervical cancer. In: Pazdur R, Coia LR, Hoskins WJ, Wagman LD, editors. Cancer Management: A Multidisciplinary Approach. Medical, Surgical and Radiation Oncology. 5th ed. Melville, NY: PRR Inc; 2001.

3. Schonland M, Bradshaw E. Some observations on cancer of the uterine cervix in Africans and Indians of Natal. S Afr J Med Sci. 1969;34: 61-71.

4. Rogo KO, Omany J, Onyango JN, Ojwang SB, Stendahl U. Carcinoma of the cervix in the African setting. Int J Gynaecol Obstet. 1990;33: 249-255.

5. Lomalisa P, Smith T, Guidozzi F. Human immunodeficiency virus infection and invasive cervical cancer in South Africa. Gynecol Oncol. 2000;77:460-463.

6. Pezzatini M, Marino G, Conte S, Catracchia V. Oncology: a forgotten territory in Africa. Ann Oncol. 2007;18:2046-2047.

7. US Centers for Disease Control and Prevention. Cervical cancer rates by race and ethnicity. Available from: http://www.cdc.gov/cancer/ cervical/statistics/race.htm. Accessed September 9, 2011.

8. KMRobinson, KB Christensen, Ottesen B, A Krasnik. Socio-demographic factors, comorbidity and diagnostic delay among women diagnosed with cervical, endometrial and ovarian cancer. Eur J Cancer Care (Engl). Sept 2000;20(5):653-661.

9. Garcés-Palacio IC, Altarac M, Kirby R, McClure LA, Mulvihill B, Scarinci IC. Contribution of health care coverage in cervical cancer screening follow-up: findings from a cross-sectional study in Colombia. Int J Gynecol Cancer. 2010;20:1232-1239.

10. Paolino M, Arrossi S. Women's knowledge about cervical cancer, Pap smear and human papillomavirus and its relation to screening in Argentina. Women Health. 2011;51:72-87.

11. Benedet JH, Bender H, Jones H 3rd, Ngan HY, Pecorelli S. FIGO staging classifications and clinical practice guidelines in management of gynecologic cancer. FIGO committee on gynecologic oncology. Int J Gynaecol Obstet. 2000;70:209-262.

12. Qasim AA. Sudanese Encyclopedia of Tribes and Genealogies. Khartoum, Sudan: Maktabat Afiruqraf; 1996.

13. Roetzheim RG, Pal N, Tennant C, et al. Effects of health insurance and race on early detection of cancer. J Natl Cancer Inst. 1999;91: 1409-1415.

14. Halpern MT, Ward EM, Pavluck AL, Schrag NM, Bian J, Chen AY. Association of insurance status and ethnicity with cancer stage at diagnosis for 12 cancer sites: a retrospective analysis. Lancet Oncol. 2008;9:189-191.

15. Ayanian JZ, Kohler BA, Abe T, Epstein AM. The relation between health insurance coverage and clinical outcomes among women with breast cancer. N Engl J Med. 1993;329:326-331.
16. Halpern MT, Bian J, Ward EM, Schrag NM, Chen AY. Insurance status and stage of cancer at diagnosis among women with breast cancer. Cancer. 2007; 110:403-111.

17. Akujobi CN, Ikechebelu JI, Onunkwo I, Onyiaorah IV. Knowledge, attitude and practice of screening for cervical cancer among female students of a tertiary institution in South Eastern Nigeria. Niger J Clin Pract. 2008;11:216-219.

18. Abotchie PN, Shokar NK. Cervical cancer screening among college students in Ghana: knowledge and health beliefs. Int J Gynecol Cancer. 2009; 19:412-416.

19. Wong LP, Wong YL, Low WY, Khoo EM, Shuib R. Knowledge and awareness of cervical cancer and screening among Malaysian women who have never had a Pap smear: a qualitative study. Singapore Med J. 2009;50:49-53.

20. Sankaranarayanan R. Royal Society of Tropical Medicine and Hygiene meeting at Manson House, London 17 January 2002. Cervical cancer in developing countries. Trans R Soc Trop Med Hyg. 2002;96: 580-585.

21. Soler ME, Gaffikin L, Blumenthal PD. Cervical cancer screening in developing countries. Prim Care Update Ob Gyns. 2000;7:118-123.

22. Miller E, Lasser KE, Becker AE. Breast and cervical cancer screening for women with mental illness: patient and provider perspectives on improving linkages between primary care and mental health. Arch Womens Mental Health. 2007;10:189-197.

23. Hoque M, Hoque E, Kader SB. Evaluation of cervical cancer screening program at a rural community of South Africa. East Afr J Public Health. 2008;5:111-116.

24. Ezem BU. Awareness and uptake of cervical cancer screening in Owerri, South-Eastern Nigeria. Ann Afr Med. 2007;6:94-98.

25. Donnelly TT. Challenges in providing breast and cervical cancer screening services to Vietnamese Canadian women: the healthcare providers' perspective. Nurse Inq. 2008;15:158-168.

26. Brewer N, Pearce N, Jeffreys M, White P, Ellison-Loschmann L. Demographic differences in stage at diagnosis and cervical cancer survival in New Zealand, 1995-2005. J Womens Health (Larchmt). 2009; 18:955-963.

27. Brookfield KF, Cheung MC, Lucci J, Fleming LE, Koniaris LG. Disparities in survival among women with invasive cervical cancer: a problem of access to care. Cancer. 2009;115:166-178.

28. Wu X, Matanoski G, Chen VW, et al. Descriptive epidemiology of vaginal cancer incidence and survival by race, ethnicity, and age in the United States. Cancer. 2008;113:73-82.

29. Nene B, Jayant K, Arrossi S, et al. Determinants of women's participation in cervical cancer screening trial, Maharashtra, India. Bull World Health Organ. 2007;85:264-272.

30. Bingham A, Bishop A, Coffey P, et al. Factors affecting utilization of cervical cancer prevention services. Salud Publica Mex. 2003;45: S408-S416.
International Journal of Women's Health

\section{Publish your work in this journal}

The International Journal of Women's Health is an international, peerreviewed open-access journal publishing original research, reports, reviews and commentaries on all aspects of women's healthcare including gynecology, obstetrics, and breast cancer. Subject areas include: Chronic conditions (migraine headaches, arthritis, osteoporosis);

\section{Dovepress}

Endocrine and autoimmune syndromes; Sexual and reproductive health; Psychological and psychosocial conditions. The manuscript management system is completely online and includes a very quick and fair peer-review system. Visit http://www.dovepress.com/ testimonials.php to read real quotes from published authors. 